\title{
CLINICAL AND MOLECULAR NEUROIMAGING CHARACTERISTICS OF BRAZILIAN PATIENTS WITH PARKINSON'S DISEASE AND MUTATIONS IN PARK2 OR PARK8 GENES
}

\author{
Orlando G.P. Barsottini, ${ }^{1,2}$, Andre C. Felício ${ }^{1,2,3}$, Patricia de Carvalho Aguiar ${ }^{1,2}$, \\ Clecio Godeiro-Juniorr, ${ }^{1,2}$, Ming C. Shih ${ }^{1,3}$, Marcelo Q. Hoexter ${ }^{1,3}$, Rodrigo A. Bressan ${ }^{1,3}$, \\ Henrique B. Ferraz ${ }^{2}$, Luiz Augusto F. Andrade
}

\begin{abstract}
Objective: To describe clinical and neuroimaging (SPECT) characteristics of Brazilian patients with Parkinson's disease (PD) and mutations in PARK2 or PARK8 genes. Method: A total of 119 patients meeting clinical criteria for PD were evaluated. Results: Of all patients studied, 13 had mutations in either PARK2 ( $\mathrm{n}=9$ ) or PARK8 genes $(\mathrm{n}=4)$. No statistically significant differences in clinical characteristics in both groups were seen. SPECT with [ $\left.{ }^{99 \mathrm{~m}} \mathrm{Tc}\right]$ TRODAT-1 showed significant differences between patient and control and the most remarkable difference was between PARK2 and control. Conclusion: The study found a frequency of mutation of $10.1 \%$ and it was most commonly seen in women. These patients had long disease course and high rates of dyskinesia after L-DOPA use. PARK8 patients did not have a relevant family history of PD.
\end{abstract}

KEY WORDS: Parkinson's disease, PARK2, PARK8, SPECT.

\section{Características clínicas e de neuroimagem molecular de pacientes brasileiros com doença de Parkinson e mutações nos genes PARK2 ou PARK8}

Resumo - Objetivo: Descrever as características clínicas e de neuroimagem (SPECT) de pacientes brasileiros com doença de Parkinson e mutações PARK2 e PARK8. Método: Foram avaliados 119 pacientes com critérios clínicos para a doença de Parkinson. Resultados: Entre os pacientes avaliados foram encontrados 13 pacientes com mutação nos genes PARK2 ( $n=9)$ ou PARK8 $(n=4)$. Não houve diferença significativa na avaliação das características clínicas entre os dois grupos. Os resultados de SPECT mostraram diferenças significativas quanto ao potencial de ligação do $\left[{ }^{99 \mathrm{~m}} \mathrm{Tc}\right]$ TRODAT-1 SPECT entre pacientes vs. controle, sendo a diferença mais pronunciada entre PARK2 e controle. Conclusão: A freqüência de mutação encontrada foi 10,1\%, sendo mais comum em mulheres. Estes pacientes apresentavam longo tempo de doença e alta prevalência de discinesias associadas ao uso da levodopa. Nossos pacientes com PARK8 não apresentaram uma história familiar relevante de doença de Parkinson.

PALAVRAS-CHAVE: doença de Parkinson, PARK2, PARK8, SPECT.

Parkinson's disease (PD) is a chronic neurodegenerative disease affecting mostly patients over the age of 50 (lateonset PD or LOPD) and it has a prevalence of 1 to $3 \%$ in patients in their seventies or more'. PD is characterized by motor and non-motor symptoms that first develop as a result of loss of dopaminergic neurons in the substancia nigra pars compacta in the mesencephalon. As for its etiology, it has been proposed a complex interaction between environmental and toxic factors, genetic predisposition and age $\mathrm{e}^{2,3}$.

PD pathogenesis may involve dysfunction of protea- some-ubiquitin and mitochondrial system that triggers a cascade of events leading to dopaminergic loss, which is a distinctive trait of this disease ${ }^{4}$. Environmental factors including well water drinking, living in rural areas, exposure to pesticides, herbicides and organic solvents have been implicated in the etiology of PD.

We describe the main clinical findings of Brazilian patients with genetically defined PD with mutations in PARK2 or PARK 8 genes as well as some molecular neuroimaging findings.

\footnotetext{
'Instituto Israelita de Ensino e Pesquisa (IIEP), Hospital Israelita Albert Einstein (HIAE), São Paulo SP, Brazil; ${ }^{2}$ Division of Movement Disorders, Universidade Federal de São Paulo (UNIFESP), Escola Paulista de Medicina (EPM), São Paulo SP, Brazil; ' ${ }^{3}$ LiNC - Laboratório Interdisciplinar de Neurociências Clínicas, UNIFESP/EPM. This study was only made possible due to the unlimited support provided by Fondation Philantropique Edmond J. Safra.
}

Received 14 August 2008, received in final form 4 November 2008. Accepted 5 December 2008.

Dr. Orlando G.P. Barsottini - Rua Cabedelo 265 - 05618-010 São Paulo SP - Brasil. E-mail: orlandobarsottini@gmail.com 


\section{METHOD}

\section{Patient recruitment}

There were 119 patients selected, both males and females of all age groups, clinically diagnosed with PD with or without family history and whose diagnosis was made according to the London Brain Bank criteria ${ }^{6}$. Although age was not considered a limiting criterion, we chose to include in the study patients with early-onset PD (EOPD), i.e., patients who developed their first PD symptoms before the age of 50 . This choice was based on the fact that genetic PD cases would be more likely to be detected. The recruitment occurred between 2006 and 2008.

Patients were clinically evaluated by the study team and selected among those seen at UNIFESP/EPM Division of Movement Disorders and at the authors' (LAFA and OGPB) private offices. After signing a free informed consent form, patients were assessed through a structured medical evaluation using the Unified Parkinson's Disease Rating Scale (UPDRS) (patients during "on" state) and Hohen and Yahr scale. In addition, $20 \mathrm{~mL}$ blood sample was drawn through peripheral venipuncture for genetic testing. Patients who did not meet the diagnostic criteria for PD were excluded from the study.

\section{Clinical data}

The following clinical data were assessed: gender; age at symptom onset; age at current evaluation; disease course; family history of PD; consanguinity; risk factors for PD; site of first symptom; first symptom; L-DOPA use; and L-DOPA-induced dyskinesia. Exposure to potential environmental risk factors (living in rural areas, well water drinking, exposure to pesticides, herbicides and organic solvents and smoking) was defined as household contact or occupational exposure to a given factor for at least two continuous years on a regular basis, at a minimum frequency of one day per month before disease onset.

\section{Mutation analysis}

Genomic DNA was extracted from peripheral whole blood using the Puregene ${ }^{\circledR}$ DNA Purification kit (Gentra Systems) or cheek swab using the ChargeSwitch gDNA Buccal Cell kit ${ }^{\circledR}$ (Invitrogen). DNA was amplified by PCR (primers and conditions available upon request). All 12 PARK2 exons and exon-intron boundaries (GenBank NM_004562) were screened by standard dideoxy nucleotide sequencing on a MegaBACE 1000 DNA Sequencer (Amersham Biosciences) and gene dosage studies were performed by real-time fluorescence based quantitative PCR on a $A B I 7300$ Sequence detector system (Applied Biosystems) using TaqMan $^{\circledR}$ fluorescently labeled probes 5'FAM or VIC (Assaysby-Design, Applied Biosystems) and TaqMan ${ }^{\circledR}$ PCR Master Mix (Applied Biosystems). Relative quantification was performed with duplex PCR in triplicates using the single copy human Beta globin gene as internal control (primers, probes and conditions available upon request). A standard curve was generated for each PARK2 exon and for Beta globin with serial dilutions of a control DNA with known concentration. Sample concentrations were inferred based on this regression curve, and a relative PARK2/ Beta globin ratio was obtained for each sample. Concentrations not within the range of the standard templates were disregarded. A normal control sample was used in all reactions. PARK2/ Beta globin ratios below 0.7 or above 1.3 were considered as deletions or duplications, respectively. All detected gene dosage variations were confirmed at least twice. PARK8 (GenBank AY792511) L1114L, I1122V, R1441C, Y1699C and G2019S mutations were screened by direct sequencing. SNPs identified in patients were screened in 144 control chromosomes either by denaturing high performance liquid chromatography (DHPLC) using the WAVE ${ }^{\circledR}$ Nucleic Acid Fragment Analysis System (Transgenomic, Omaha, NE), or by direct sequencing ${ }^{7}$.

\section{Imaging procedures and analysis}

SPECT scans were performed with [ $\left.{ }^{99 \mathrm{~m}} \mathrm{Tc}\right]-T R O D A T-1$, a radiotracer with high selectivity and specificity for the Dopamine Transporter (DAT). TRODAT-1 kits were produced by the Institute of Nuclear Energy Research (INER-Taiwan R.O.C.). Images were acquired four hours after the injection of $814 \mathrm{MBq}( \pm 74)$ of [99mTc]-TRODAT-1. DAT density was calculated with binding potential (DAT-BP) using regions of interests (ROI) bilaterally drawn in the striatum (STR) and the occipital cortex (OCC- background). BP was calculated with the formula striatum (STR-OCC)/OCC. This protocol is already published elsewhere ${ }^{8}$.

\section{Statistical analysis}

The correlation of clinical data between groups of patients with gene mutations was analyzed using Fisher's exact test and chi-square test for categorical variables and non-paired Student's t-test for continuous variables (parametric data). A $5 \%$ significance level was set and $p<0.05$ was considered significant. The descriptive and statistical analyses were performed using Prisma software program 3.0.

The study was approved by UNIFESP-EPM and IIEP-HIAE Research Ethics Board.

\section{RESULTS}

Table 1 summarizes the main clinical and epidemiological characteristics of patients studied. Of 119 patients assessed, 13 had mutations in either PARK2 $(\mathrm{n}=9)$ or PARK8 genes $(n=4)$. Since a couple of PARK2 patients were consanguineous, the actual frequency of mutation found in our study was $10.1 \%$ (12/118). Most patients studied were women, especially in PARK8 group. Age at symptom onset was $32.4 \pm 11.3$ years and $40.4 \pm 7.1$ years in $P A R K 2$ and PARK8 groups, respectively. Both groups had a disease course of more than 10 years at the time of genetic testing. In PARK2 group, $77 \%$ of patients had family history of PD compared to $50 \%$ in PARK8 group. Consanguinity was seen in PARK8 group only (75\%). Of PD risk factors selected for this study, $100 \%$ of patients in PARK2 group and $50 \%$ in PARK8 group met the criteria for the variables 
Table 1. Clinical characteristics of Brazilian Parkinson's disease (PD) patients with mutations in either PARK2 or PARK8 genes.

\begin{tabular}{|c|c|c|c|}
\hline & PARK2 & PARK8 & PARK2 vs. PARK 8 \\
\hline Patients (n) & $n=9 / 119$ & $n=4 / 119$ & \\
\hline Female-to-male ratio & 1.75 & 4 & $\mathrm{p}=1.0 ; \mathrm{NS}^{\mathrm{a}}$ \\
\hline Age at symptom onset ${ }^{1}$ & $32.4 \pm 11.3$ years & $40.4 \pm 7.1$ years & $\mathrm{p}=0.19 ; N S^{\mathrm{b}}$ \\
\hline Disease course $^{1}$ & $15.3 \pm 11.4$ years & $10.2 \pm 10.4$ years & $\mathrm{p}=0.75 ; N \mathrm{~S}^{\mathrm{b}}$ \\
\hline Family history of PD & $7 / 9 ; 77 \%$ & $2 / 4 ; 50 \%$ & $\mathrm{p}=0.6 ; \mathrm{NS}^{\mathrm{a}}$ \\
\hline Consanguinity & $0 / 9 ; 0 \%$ & $3 / 4 ; 75 \%$ & $\mathrm{p}=0.06 ; \mathrm{NS}^{\mathrm{a}}$ \\
\hline Risk factors for PD & $9 / 9 ; 100 \%$ & $2 / 4 ; 50 \%$ & $\mathrm{p}=0.25 ; \mathrm{NS}^{\mathrm{a}}$ \\
\hline \multirow[t]{3}{*}{ Site of first symptom } & Hand $/$ forearm $n=6 / 9$ & Hand/forearm $n=4 / 4$ & $\mathrm{p}=0.57 ; \mathrm{NS}^{\mathrm{c}}$ \\
\hline & Foot $/$ leg $n=4 / 9$ & Foot $/$ leg $n=1 / 4$ & \\
\hline & Head $n=1 / 9$ & Head n=0/4 & \\
\hline \multirow[t]{4}{*}{ First symptom ${ }^{2}$} & $T n=7 / 9$ & $T n=2 / 4$ & $\mathrm{p}=0.25 ; \mathrm{NS}^{\mathrm{c}}$ \\
\hline & $R n=2 / 9$ & $R \mathrm{n}=0 / 4$ & \\
\hline & $B n=0 / 9$ & $B n=1 / 4$ & \\
\hline & Mixed $n=2 / 9$ & Mixed $n=1 / 4$ & \\
\hline L-DOPA use? & $9 / 9$ & $3 / 4$ & $\mathrm{p}=0.55 ; \mathrm{NS}^{\mathrm{a}}$ \\
\hline Dyskinesia due to L-DOPA? & $6 / 9$ & $3 / 3$ & $\mathrm{p}=0.51 ; \mathrm{NS}^{\mathrm{a}}$ \\
\hline Time to L-DOPA-dyskinesia & 4.2 years $(n=6)$ & 4 years $(n=3)$ & $\mathrm{p}=0.7 ; N S^{\mathrm{b}}$ \\
\hline \multirow[t]{3}{*}{ Dyskinesia severity ${ }^{3}$} & $M n=3$ & $M n=0$ & $p=0.56 ; N S^{b}$ \\
\hline & Mo $n=1$ & Mo $n=3$ & \\
\hline & $S n=2$ & $S n=0$ & \\
\hline
\end{tabular}

'Mean \pm Standard deviation; ${ }^{2} \mathrm{~T}$, resting tremor; R, rigidity; B, bradykinesia and/or I, postural instability; ${ }^{3} \mathrm{M}$, mild; Mo, moderate; $\mathrm{S}$, severe; ${ }^{\mathrm{a}} \mathrm{Fisher's} \mathrm{exact} \mathrm{test;}{ }^{\mathrm{b}} \mathrm{Non}$-paired Student's t-test; ${ }^{\mathrm{C}} \mathrm{Chi}$-square test.

Table 2. Detailed description of mutations found in the patients studied.

\begin{tabular}{|c|c|c|c|}
\hline & Gene & $\begin{array}{l}\text { Exon/ } \\
\text { Intron }\end{array}$ & Nucleotide / Mutated Protein \\
\hline 1 & PARK2 & EX 1 & EX1del (het)/without traduction \\
\hline 2 & PARK2 & EX 2 & 156_157ins T (het)/D53X* \\
\hline 3 & PARK2 & EX 2 & 156_157ins T (het)/D53X* \\
\hline 4 & PARK2 & EX 3 & EX3del (het)/N58QfsX39 \\
\hline 5 & PARK2 & EX 3 & EX3del (het)/N58QfsX39 \\
\hline 6 & PARK2 & EX 3 & EX3del (het)/N58QfsX39 \\
\hline \multirow[t]{2}{*}{7} & PARK2 & EX 3 & EX3del (het)/N58QfsX39 \\
\hline & & EX 6 & A633T (hom)/K211N \\
\hline 8 & PARK2 & EX 11 & EX11del(het)/A390EfsX6 \\
\hline 9 & PARK2 & IN 11 & 1286-3G>C(hom)/G429EfsX5 \\
\hline 10 & PARK8 & EX 41 & G6055A (het)/G2019S \\
\hline 11 & PARK8 & EX 41 & G6055A (het)/G2019S \\
\hline 12 & PARK8 & EX 41 & G6055A (het)/G2019S \\
\hline 13 & PARK8 & EX 41 & G6055A (het)/G2019S \\
\hline
\end{tabular}

EX, exon; IN, intron; het, heterozigous; hom, homozigous. studied. The first symptom reported in both groups was resting tremor, most commonly affecting the hand/forearm. The majority of patients took L-DOPA $(100 \%$ and $75 \%$ in PARK2 and PARK8 groups, respectively). The rate of dyskinesia was $66 \%$ and $100 \%$ in PARK 2 and PARK 8 groups, respectively. The mean time between L-DOPA use and dyskinesia onset was 4.2 years $(n=6)$ in PARK2 patients compared to 4 years $(n=3)$ in PARK8 group.

A statistical comparison of clinical characteristics between PARK2 and PARK8 groups did not show any significant differences as shown in Table 1.

Among those exposed to environmental risk factors, they were mostly exposed to rural living or well water drinking during their first and second decades of life. Exposure to other products (pesticides, herbicides or organic solvents) and smoking occurred mainly during their second and third decades of life. Well water drinking was significantly more prevalent $(p=0.004)$ in EOPD compared to controls. On Table 2 we detailed the mutations we found on both groups of patients with PARK2 and 8 .

Table 3 shows the results of the binding potential (DAT-BP) of $\left[{ }^{99 \mathrm{~m}} \mathrm{Tc}\right]$ TRODAT-1 SPECT in 2 patients (1 in 
Table 3. TRODAT-1 SPECT binding potential (DAT-BP) in PARK2 and PARK8 patients compared to a sex-and age-matched healthy control subject.

\begin{tabular}{lcccccccc}
\hline & $\begin{array}{c}\text { Age at } \\
\text { SPECT }(y)\end{array}$ & $\begin{array}{c}\text { Disease } \\
\text { duration }(\mathrm{y})\end{array}$ & $\begin{array}{c}\text { Off } \\
\text { H\&Y }\end{array}$ & $\begin{array}{c}\text { On total } \\
\text { UPDRS }\end{array}$ & $\begin{array}{c}\text { BP R } \\
\text { caud }\end{array}$ & $\begin{array}{c}\text { BP R } \\
\text { put }\end{array}$ & $\begin{array}{c}\text { BP L } \\
\text { caud }\end{array}$ & $\begin{array}{c}\text { BP L } \\
\text { put }\end{array}$ \\
\hline PARK2 & $36 ; \mathrm{F}$ & 11 & 3.0 & 51 & 0.80 & 0.45 & 0.73 & 0.50 \\
PARK8 & $43 ; \mathrm{F}$ & 11 & 3.0 & 60 & 0.85 & 0.66 & 0.85 & 0.38 \\
control & $39 ; \mathrm{F}$ & $\mathrm{NA}$ & $\mathrm{NA}$ & $\mathrm{NA}$ & 1.11 & 0.97 & 0.97 & 0.85 \\
PARK2/control & & & & & $27.63 \%$ & $59.13 \%$ & $34.47 \%$ & $54.63 \%$ \\
PARK8/control & & & & & $23.15 \%$ & $12.73 \%$ & $12.64 \%$ & $0.08 \%$ \\
\hline
\end{tabular}

NA, non-applicable; H\&Y, modified Hoehn \& Yahr scale; UPDRS, unified Parkinson's disease rating scale; BP, binding potential; R, right; L, left; caud, caudate; put, putamen.

PARK2 and 1 in PARK8 group) compared to a healthy control, matched by age and gender.

\section{DISCUSSION}

In recent years the knowledge on the etiology of PD has gained momentum with advances in molecular genetics. Families with autosomal dominant disease forms and pathogenesis associated to the presence of Lewy bodies have been evidenced to be related to alpha-synuclein gene (PARKI) $)^{9}$. Other autosomal dominant forms of PD have been associated to LRRK2 gene (PARK8) and have been largely studied in recent years due to its high frequency of occurrence ${ }^{10,11}$. Autosomal recessive forms with EOPD have also been described associated to PARKIN (PARK2), DJ-1 (PARK6) and PINK-1 genes (PARK7) ${ }^{3}$. All these genetic mutations lead to abnormalities in proteins (e.g, ubiquitin), oxidative stress, and mitochondria and today it can be assumed that PD comprises a heterogeneous group of diseases with a wide range of clinical and pathological presentations.

Of all patients assessed in our study, only patients with mutations in PARK2 and PARK 8 genes are described here, since tests are still ongoing with DJ-1 and PINK-1. Of 119 patients studied, 9 had mutation in PARK2 and 4 in PARK8 gene, a frequency of mutation of $10.1 \%$ in these two genes only.

PARK2, a gene for autosomal recessive juvenile parkinsonism, has been first described in patients in Japan. The gene locus for this form of parkinsonism was mapped in 6q25.2-27 chromosome ${ }^{12}$. PARK2 patients develop EOPD around the age of 20-30 and show distinct clinical characteristics compared to idiopathic PD (slow progress, dystonia at onset involving lower limbs, and dyskinesia after low-dose L-DOPA) ${ }^{13}$. Interestingly, pathologically, these patients do not have Lewy bodies ${ }^{12}$. PARKIN gene is believed to be associated to most sporadic cases developing before the age of 20 and nearly $25 \%$ of cases seen between the age of 20 and 35. The protein produced by PARKIN gene seems to be associated to protein ubiquitination, which acts as a ligase in the proteasome-ubiquitin system, eliminating abnormal or mutant proteins. When they accumulate, seemingly they are cytotoxic and cause cell injury ${ }^{14}$.

In PARK2 group of our study, their main characteristics were EOPD, long disease course, and common family history of PD but no case of consanguinity in first-degree ancestors was found. Their first symptom was resting tremor developing in hand/forearm. Of 9 patients who reported L-DOPA use, 66\% developed dyskinesia, which was reported after on average 4.2 years of drug use compared to 4 years in PARK8 group. The most frequent mutation found was Ex3 deletion (Table 2).

Those with mutation in PARK2 gene are more commonly seen among EOPD patients. While many patients have family history of PD, as seen in our study, sporadic cases have been also reported developing at the age of 40 years ${ }^{12-14}$. Their clinical presentation can be similar to idiopathic PD but they remarkably have dystonia in lower limbs, which was not seen in our group. Disease progression is often slower than in idiopathic PD but they tend to develop early-onset dyskinesia after low-dose L-DOPA ${ }^{12-14}$. The rate of dyskinesia $(66 \%)$ found in our study is more characteristically seen in LOPD patients.

Mutations in PARK8 gene are more frequently described in LOPD patients, and they are either sporadic or familial ${ }^{10,11}$. They seem to be clinically and pathologically undistinguishable from idiopathic PD. The protein produced by the mutation in LRRK2 gene is called dardarin (the protein encoded by LRRK2 gene is called dardarin, and not by the mutation). Five different mutations have been described associated to this gene and the G2019S is the most common ${ }^{15}$. They are clinically very similar to sporadic cases of PD. They usually develop in the sixth decade of life and progress with complications due to L-DOPA use similar to sporadic disease. They can show a wide range of pathology presentations including disease associated to Lewy bodies, nigral degeneration and tau 
protein aggregation (PSP-like) ${ }^{14,15}$. Very recently it has been shown to express different phenotypes, like corticobasal syndrome and primary progressive aphasia ${ }^{16}$.

In our study, the main characteristics of PARK 8 group were EOPD especially affecting women, long disease course, and non-relevant family history of PD though $75 \%$ of patients had first- or second-degree consanguinity. Their first symptom was resting tremor affecting the hand/forearm and all 3 patients who took L-DOPA developed dyskinesia. The most frequent mutation we found on PARK8 gene was the G2019S (Table 2).

Mutations in LRRK2 gene are the most common cause of monogenetic PD in patients with LOPD, cases are evenly distributed in both men and women but they have family history of autosomal dominant inheritance. This mutation has variable penetrance and it is thus the most frequently seen in sporadic cases of PD. Its clinical presentation is similar to idiopathic PD, it usually develops after the age of 40 with predominance of psychiatric symptoms ${ }^{3}$.

It should be noted that patients with mutation in PARKIN gene associated to G2019S mutations (PARK8) have recently been identified, which suggests digenic transmission of DP ${ }^{17}$. However, in our study, we did not find any similar cases.

Molecular imaging studies assessing dopaminergic and even non-dopaminergic systems have now been used as biomarkers for $\mathrm{PD}^{18}$. We recently reviewed data on molecular imaging techniques in patients with genetic forms of PD (PARK1, 2, 6, 7 and 8) and clinically unclear cases of parkinsonism ${ }^{19-21}$. Neuroimaging data on PARK2 and PARK 8 patients show a pattern similar to the sporadic forms of PD, except for post-synaptic involvement with greater DAT loss in the early stages of disease and slower progression in PARK2 patients. Data from the patients we scanned showed greater difference in the PARK2 patient when compared to a matched control. Further studies with larger samples are needed to further evaluate these differences.

A sample of these patients herein studied, comprising 72 EOPD patients, was detailed studied for genetic characteristics and risk factors of PD showing that well water drinking exposure represents a risk factor for EOPD and the PARK2 coding polymorphism Val380Leu might be interacting with environmental factors acting as a disease modifier?.

The present study had some limitations: small number of genetic cases and SPECT scans and selection bias, where there were included EOPD patients with higher prevalence of mutations. The $10 \%$ frequency of mutation found in our study would probably be lower in a group of patients with late-onset Parkinson's disease, i.e., the younger the patients with PD the more likely they have mutations. It should be stressed that we are currently testing PARK6 or PARK7 mutations in our sample. PARK1 mutation has not been investigated due to its low prevalence.

In conclusion, in our group of PARK2 and PARK8 patients, the frequency of mutation was $10.1 \%$, predominantly in women. These patients had long disease course (around 10 years) and high rates of dyskinesia after LDOPA use (especially in those with PARK8 mutation), and tremor was the first symptom seen in all cases. Compared to PARK2 patients, PARK8 patients did not have a relevant family history of PD. SPECT results showed significant differences between patient vs. control, which were more pronounced between PARK2 vs. control.

\section{REFERENCES}

1. Zhang ZX, Roman GC. Worldwide occurrence of Parkinson's disease: an update review. Neuroepidemiology 1993;12:195-208.

2. Semchuk KM, Love EJ, Lee RG. Parkinson's disease: a test of the multifactorial etiologic hypothesis. Neurology 1993;43:1173-1180.

3. Gosal D, Ross AO, Toft OM. Parkinson's disease: the genetics of a heterogeneous disorder. Eur J Neurol 2006;13:616-627.

4. McKaught KSP, Olanow CW. Proteolytic stress: a unifying concept for the etiopathogenesis of Parkinson's disease. Ann Neurol 2003;55:73-86.

5. Priyadarshi A, Khuder SA, Schaub EA, Priyadarshi SS. Environmental risk factors and Parkinson's disease: a metaanalysis. Environ Res 2001;86:122-127.

6. Hughes AJ, Daniel SE, Kilford L, Lees AJ. Accuracy of clinical diagnosis of idiophatic Parkinson's disease: a clinico-pathological study of 100 cases. J Neurol Neurosurg Psychiatry 1992;55:181-184.

7. Carvalho Aguiar P, Lessa PS, Godeiro-Junior C, et al. Genetic and environmental findings in early-onset Parkinson's disease Brazilian patients. Mov Disord 2008; 23:1228-1233.

8. Shih MC, Andrade LAF, Amaro E Jr, et al. Higher nigrostriatal dopamine neuron loss in early than late onset Parkinson's disease? A [ ${ }^{99 \mathrm{~m}} \mathrm{Tc}$ ]-TRODAT-1 SPECT study. Mov Disord 2007;22:863-866.

9. Berg D, Niwar M, Mass S, et al. Alpha-synuclein and Parkinson's disease: implications from the screening of more than 1,900 patients. Mov Disord 2005;20:1191-1194

10. Zimprich A, Biskup S, Leitner P, et al. Mutations in LRRK2 cause autosomal-dominant parkinsonism with pleomorphic pathology. Neuron 2004;44:595-600.

11. Gilks WP, Abou-Sleiman PM, Gandhi S, et al. A common LRRK2 mutation in idiopathic Parkinson's disease. Lancet 2005;365:415-416.

12. Kitada T, Asakawa S, Hattori N, et al. Mutations in the parkin gene cause autosomal recessive juvenile parkinsonism. Nature 1998;392:605-608

13. Khan NL, Graham E, Critchley P, et al. Parkin disease: a phenotypic study of a large case series. Brain 2003;126:1279-1292.

14. Shimura H, Hattori N, Kubo S, et al. Familial Parkinson disease gene product, parkin, is a ubiquitin-protein ligase. Nat Genet 2000;25:302-305.

15. Di Fonzo A, Rohe CF, Ferreira J, et al. A frequent LRRK2 gene mutation associated with autosomal dominant Parkinson's disease. Lancet 2005;365:412-415.

16. Chen-Plotkin AS, Yuan W, Anderson C, et al. Corticobasal syndrome and primary progressive aphasia as manifestations of LRRK2 gene mutations. Neurology 2008;70:521-527.

17. Dächsel JC, Mata IF, Ross OA, et al. Digenic parkinsonism: investigation of the synergistic effects of PRKN and LRRK2. Neurosci Lett 2006;410:80-84.

18. Shih MC, Amaro-Jr E, Ferraz HB, et al. Neuroimaging of the dopamine transporter in Parkinsons disease: first study using [ [99m Tc]-TRODAT-1 and SPECT in Brazil (in Portuguese). Arq Neuropsiquiatr 2006;64:628-634

19. Bressan RA, Shih MC, Hoexter MQ, et al. Can molecular imaging techniques identify biomarkers for neuropsychiatric disorders? Rev Bras Psiquiatr 2007;29:102-104.

20. Shih MC, Felicio AC, Godeiro-Junior C, et al. Molecular imaging in hereditary forms of parkinsonism. Eur J Neurol 2007;14:359-368.

21. Felicio AC, Shih MC, Godeiro-Junior C, et al. Molecular imaging studies in Parkinson's disease: reducing diagnostic uncertainty. Neurologist 2008; in press. 